Journal of Applied Pharmaceutical Science Vol. 5 (10), pp. 101-106, October, 2015

Available online at http://www.japsonline.com

DOI: $10.7324 / \mathrm{JAPS} .2015 .501017$

ISSN 2231-3354 (cc) BY-NC-sA

\title{
Rates of Feeding and Assimilation in the Silkworm Bombyx mori, as Influenced by Methoprene
}

\author{
K S Santhy \\ Department of Zoology, Avinashilingam Institute for Home Science and Higher Education for Women, Coimbatore, India.
}

\begin{tabular}{|c|c|}
\hline ARTICLE INFO & ABSTRACT \\
\hline Article history: & \multirow{10}{*}{$\begin{array}{l}\text { Juvenile Hormone Analogues (JHAs) which prolong the larval life in insects have been long tried for the } \\
\text { improvement of silk production in silkworm. Study of nutritional parameters like consumption, digestion and } \\
\text { utilization of sericigenous insect is considered to be an important field of work for better management and } \\
\text { development of the sericulture industry apart from its physiological importance. An elaborate study on nutritional } \\
\text { indices was presently undertaken to elucidate the role of JHA in improving the overall production of cocoons and } \\
\text { thereby for the improvement of sericulture industry. Manta, a JHA, was applied at various concentrations on } \\
\text { larvae of both sexes and the calorific and nutritional indices were analysed. Study of nutritional parameters of } \\
\text { Bombyx mori revealed positive correlations between males females and controls with respect to consumption, } \\
\text { assimilation and production. Of the dosages administered, } 0.75 \mu \mathrm{g} \text { and } 1.0 \mu \mathrm{g} \text { dosages were found to be better } \\
\text { treatments with regard to the parameters. From the overall energetics of the present study, it is clear that the } \\
\text { concentration of Manta applied had a significant positive correlation with consumption, egestion, production and } \\
\text { ECD. }\end{array}$} \\
\hline Received on: & \\
\hline /08/2015 & \\
\hline Accepted on: 02/09/2015 & \\
\hline Available online: $28 / 10 / 2015$ & \\
\hline Key words: & \\
\hline Juvenile hormone, analogue, & \\
\hline Manta, silk, larvae, nutrition. & \\
\hline & \\
\hline & \\
\hline
\end{tabular}

\section{INTRODUCTION}

Juvenile hormone (JH) controls silk gland function, prevents their degeneration and can indirectly cause an increase in silk production (Sehnal and Akai, 1981; Unni et al., 2010). Juvenile Hormone Analogue (JHA) mimics the action of insect specific JHA and delays the larval maturation and increases silk production (Shibukawa and Akai, 1981; Srivastava and Upadhyay, 2013). However, response to such treatments varies depending on the dosage, the time (developmental stage) and the number of applications (Nagendraradhya and Kumar, 2013). The different races of silkworms respond in different ways to the treatment of JHA (Wu et al., 2013). Scanning of literature reveals that there is no substantial research contribution regarding the usage of JHA for silk production in Indian conditions. Commercial utilization of this technique will be possible only through a detailed investigation which will enlighten on the effective dose for mass application. Juvenile Hormone Analogues (JHAs) which prolong the larval life in insects have been long tried for the improvement of silk

\footnotetext{
* Corresponding Author

Email:dr.santhyanandan@gmail.com
}

production in silkworm, B. mori. As early as in 1971, Akai and Kobayashi have reported the increased accumulation of silk protein accompanied by prolongation of larval life in $B$. mori on treatment with synthetic JHAs. Methoprene, the synthetic JHA was developed as a commercial drug with trade name Manta in 1977. Scientists from the Republic of Korea have developed another JHA with the trade name 'Manina' ZR - 512, a product of Zoecon corporation, USA, contains hydroprene as juvenile hormone mimic. Study of nutritional parameters like consumption, digestion and utilization of sericigenous insect is considered to be an important field of work for better management and development of the sericulture industry apart from its physiological importance (Lokeshwari and Shantibala, 2010). In lepidopterans, both brain hormone and $\mathrm{JH}$ seemed to stimulate feeding and the amount of food ingested induced enzyme production (Miranda et al., 2002). Most of the insects continue to feed throughout their life thus supplying the essential materials for body maintenance, growth and reproduction. Exogenous application of the JHA was found to prolong the larval life which resulted in increased consumption and inturn affected the nutritional indices. An elaborate study on nutritional indices was presently undertaken to elucidate the role of JHA in improving the overall production of cocoons and thereby for the improvement of sericulture industry. 


\section{MATERIALS AND METHODS}

\section{Test hormone}

JHA, Manta (Methoprene), the product of Ohtusuka Pharmaceuticals, Osaka, Japan was a kind gift of Dr. H. Numata, Osaka city University, Osaka, Japan.

\section{Hormone application}

Freshly ecdysed fifth instar larvae of $B$. mori were selected from stock culture and were assorted into males and females. Sexes were separated by identifying the sex marks found on the postero-ventral side of the larvae. JHA, Methoprene (Manta $6.25 \mathrm{mg}$ in $5 \mathrm{ml}$ - stock) was diluted with distilled water and topically applied on 4-5th segment of the larvae using a micropipette between 48-72 hrs after fourth ecdysis.

Freshly ecdysed, fifth instar male and female larvae were grouped separately, weighed and maintained individually in 250 $\mathrm{ml}$ plastic containers. The larvae were fed ad-libitum with fresh mulberry leaves. In both sexes, weighed larvae were divided into 6 groups, five for the hormone treatments and one for control. For the present investigation the dosages $0.10 \mu \mathrm{g}\left(\mathrm{T}_{1}\right), 0.25 \mu \mathrm{g}\left(\mathrm{T}_{2}\right)$, $0.5 \mu \mathrm{g}\left(\mathrm{T}_{3}\right), 0.75 \mu \mathrm{g}\left(\mathrm{T}_{4}\right), 1 \mu \mathrm{g}\left(\mathrm{T}_{5}\right)$ and control were selected. Five replications were maintained for each group.

\section{Collection of food remains and faeces}

Unfed leaves and faecal pellets were removed every day before offering the next consignment of food with least disturbance to the larvae and the collected samples were dried separately at $80{ }^{\circ} \mathrm{C}$ to a constant weight. Care was taken to separate fine unfed food particles from the faecal pellets.

\section{Gravimetry}

All weighings were analysed using an electronic balance with an accuracy of $0.0001 \mathrm{mg}$. The accuracy of the balance was checked for every ten weighing. To find the dry matter content of the test larvae belonging to different groups, a few test larvae were sacrificed at the beginning as well as at the end of the fifth instar and dried at $80{ }^{\circ} \mathrm{C}$ to a constant weight. ${ }^{[9]}$ Dried materials of sample worms, faeces and food were powdered and stored for calorific analysis.

\section{Calorimetry}

Calorific content of the samples was determined using a bomb calorimeter, the supplied outfit of which is recommended by the ISI (IS: 1359 - 1959), BSI (BSI : 10161 Part 5 : 1967) and the institute of petroleum (IP/2/63T).

\section{Calculation of nutritional indices}

The scheme of energy budget followed in the present study was based on the IBP formula (Petrusewicz and Macfayden, 1970) usually represented as

$$
\mathrm{C}=\mathrm{P}+\mathrm{R}+\mathrm{F}+\mathrm{U}
$$

Where C - Food energy consumed; P-Growth; R-Energy released as heat due to metabolism; F+U - Loss of energy through faeces and nitrogenous excretory products.

In majority of the insects, the quantity of uric acid (U) excreted in the faeces is negligible and amounts to 0.2 to 0.5 per cent of the total quantity of faeces egested. The food consumption of the fifth instar larvae was calculated by adding daily consumption/larva. The mean faecal weight/larva was also calculated similarly. The above quantitative estimation of $\mathrm{C}$ was made in terms of Joules. Food energy converted into body substance ( $\mathrm{P}=$ Growth) was estimated as the difference between the energy content of the test larvae at the beginning and at the end of fifth instar. Food energy assimilated (A) was calculated by substracting the mean faecal energy from that of food energy consumed.

$$
\mathrm{A}=\mathrm{C}-(\mathrm{F}+\mathrm{U})
$$

Rates of consumption (Cr), Assimilation (Ar) and Production (Pr) were calculated by dividing the respective amounts of energy by the product of mid body weight $(\mathrm{g})$ of the worms and the duration (days) required for the completion of the fifth instar; the rates were expressed in terms of Joules/g live larva/day (Table 1). Efficiencies of conversion of ingested matter to body substance (ECI) and digested matter to body substances (ECD) were calculated relating $\mathrm{P}$ to $\mathrm{C}$ and $\mathrm{A}$ separately and expressed as percentage.

\section{RESULTS}

Study of nutritional parameters of sericigenous insects is considered to be an important field of work for better management and development of the sericulture industry apart from its physiological importance.

Table 1: Formula used to calculate the parameters of nutritional indices

\begin{tabular}{lc}
\hline \multicolumn{1}{c}{ Parameter } & Formula \\
\hline Consumption Rate (Cr) & C (Joules/Larva) \\
Assimilation Rate (Ar) & Mid body weight (g)X Duration (days) \\
Production Rate (Pr) & Mid body weight (g)X Duration (days) \\
Assimilation Efficiency (AE) & $\frac{\mathrm{A} \text { (Joules } / \text { Larva) }}{\mathrm{C}} \times 100$ \\
Efficiency of conversion of ingested matter to body substance (ECI) & $\frac{\mathrm{P}}{\mathrm{C}} \times 100$ \\
Efficiency of conversion of digested matter to body substance (ECD & $\mathrm{P} \times 100$ \\
\hline
\end{tabular}


The male fifth instar larvae of control group consumed was $91.82 \mathrm{~kJ} /$ larva and increased with increasing concentration of Manta. A dose dependent increase observed was evident from Table 2 and 4; maximum consumption being $106.65 \mathrm{~kJ} /$ larva in 1.0 $\mu \mathrm{g}$ dosage and minimum being $94.65 \mathrm{~kJ} / \mathrm{larva}$ in $0.1 \mu \mathrm{g}$ respectively.

From the results it is clear that a positive and significant correlation $(\mathrm{r}=0.560 ; \mathrm{P}=0.01)$ exists between Methoprene treatment and its consumption. In females, maximum consumption was recorded in $0.75 \mu \mathrm{g}$ dosage $(105.70 \mathrm{~kJ} /$ larva) which was found to be on par with $0.5 \mu \mathrm{g}(104.78 \mathrm{~kJ} / \mathrm{larva}), 1.0 \mu \mathrm{g}(102.11 \mathrm{~kJ} / \mathrm{larva})$ and $0.25 \mu \mathrm{g}(101.56 \mathrm{~kJ} /$ larva) while control recorded minimum consumption (91.73 kJ/larva). A significant positive correlation was observed in this study.

\section{Egestion}

The energy lost via faeces increased with increase in concentration of hormone applied (Table 2, Figure 1). In control larvae, egestion was $46.43 \mathrm{~kJ} /$ larva in males and $54.55 \mathrm{~kJ} /$ larva in females. It increased to 68.48 in male and $73.05 \mathrm{~kJ} / \mathrm{larva}$ in female at $1.0 \mu \mathrm{g}$ dosage. However, in females, maximum egestion was recorded in $0.75 \mu \mathrm{g}$ dosage $(73.21 \mathrm{~kJ} /$ larva $)$, which was found to be on par with $1.0 \mu \mathrm{g}(73.05 \mathrm{~kJ} /$ larva) and $0.5 \mu \mathrm{g}$ dosages $(72.00$ $\mathrm{kJ} /$ larva). The percentage elevation over control for $1.0 \mu \mathrm{g}$ dosage was 47 in male and 33 in female. On relating the concentration of hormone applied and egesta, a significant positive correlation was observed $(r=0.758$ in male and 0.816 in female; $P=0.01)$. The data on regression analysis showed that there exists a curvelinear relationship with quadratic equation $\mathrm{Y}=47.1+38 \mathrm{x}-17 \mathrm{x}^{2}$ in male and $\mathrm{Y}=55.86+49 \mathrm{x}-32 \mathrm{x}^{2}$ in female.

\section{Assimilation}

The assimilated energy of the control male larvae was $45.50 \mathrm{~kJ} /$ larva and it gradually decreased as the hormone concentration increased (Table 2, Figure 1). At $0.1 \mu \mathrm{g}$ dosage the assimilated energy of male and female was 45.72 and 35.26 $\mathrm{kJ} /$ larva respectively. At $1.0 \mu \mathrm{g}$ concentration, it declined to 38.16 and $29.56 \mathrm{~kJ} / \mathrm{larva}$ in male and female respectively. The data were not statistically significant.

\section{Production}

Interestingly the conversion of energy into the larval body substance increased with an increase in the hormone concentration (Table 2, Figure 1). In males, $1.0 \mu \mathrm{g}$ dosage showed a maximum increment of $17 \%$ over control and was found to be on par with all the dosages applied. In females, the highest increment was observed in $0.75 \mu \mathrm{g}$ dosage, i.e., $20 \%$ over control. From the data it was obvious that a positive and significant correlation $(\mathrm{r}=$ 0.464 in male and $r=0.625$ in females at $P=0.01$ ) exists between the concentration of hormone applied and production (Table 2). Regression analysis revealed a curvilinear relationship ( $\mathrm{Y}=10.92$ $+2 \mathrm{x}-\mathrm{x}^{2} ; \mathrm{r}^{2}=0.23$ in male and $\mathrm{Y}=12.24+6 \mathrm{x}-5 \mathrm{x}^{2} ; \mathrm{r}^{2}=0.67$ in female).

\section{Consumption rate}

In the fifth instar male larvae of control group, the consumption rate was $6221.86 \mathrm{~J} / \mathrm{g}$ live larva/day which declined slowly with increasing concentration of Manta (Table 2, Figure 1). The lowest consumption rate was recorded in $1.0 \mu \mathrm{g}$ treatment ie., $4955.53 \mathrm{~J} / \mathrm{g}$ live larva/day. A similar trend was observed in female larvae, the lowest value being $4238.46 \mathrm{~J} /$ live larva/day in $1.0 \mu \mathrm{g}$ dosage. From the data, it was clear that a negative and significant linear relationship $\left(\mathrm{Y}=6116.50-2188 \mathrm{x}+995 \mathrm{x}^{2}\right.$ in male and $\mathrm{Y}=$ $5444.57-3016 x+1821 x^{2}$ in female) exists between the hormone dosage and consumption rate. On relating hormone dosage to consumption rate, a significant negative correlation was observed $(\mathrm{r}=-0.640$ in male and $\mathrm{r}=-0.859$ in female, for $\mathrm{P}=0.01)$.

\section{Assimilation rate}

In the control group male and female larvae, the assimilation rate was 3094.31 and $2117.19 \mathrm{~J} / \mathrm{g}$ live larva/day respectively (Table 2, Figure 1). But the rate declined with the increase in the concentration of Manta. At the highest concentration of $1.0 \mu \mathrm{g}$ dosage it decreased to $1998.97 \mathrm{~J} / \mathrm{g}$ live larva/day in male and $1190.69 \mathrm{~J} / \mathrm{g}$ live larva/day in female. On relating hormone dosage to assimilation rate, a significant negative correlation was observed $(r=-0.813$ in male and $r=-0.839$ in female for $\mathrm{P}=0.01$ ). A highly significant value of the co-efficient of determination $\mathrm{r}^{2}=0.67$ in male and 0.73 in female at $\mathrm{P}=0.01$ ) was noted in regression analysis.

Table 2: Correlation co-efficient ( $\mathrm{r}$ ) and co-efficient of determination $\left(\mathrm{r}^{2}\right)$ obtained between different concentrations of Manta and nutritional indices of fifth instar larvae.

\begin{tabular}{|c|c|c|c|c|}
\hline \multirow{2}{*}{ Parameter } & \multicolumn{2}{|c|}{ Correlation Co-efficient (r) } & \multicolumn{2}{|c|}{ Co-efficient of determination $\mathbf{r}^{2}$} \\
\hline & Male & Female & Male & Female \\
\hline Consumption & $0.560^{* *}$ & $0.646^{* *}$ & $0.36^{* * *}$ & $0.70 * *$ \\
\hline Egestion & $0.758 * *$ & $0.816^{* *}$ & $0.60 * *$ & $0.84 * *$ \\
\hline Assimilation & NS & $-0.444 * *$ & NS & $0.20 * *$ \\
\hline Production & $0.464 * *$ & $0.625 * *$ & $0.23 *$ & $0.67 * *$ \\
\hline Consumption rate & $-0.640 * *$ & $-0.859 * *$ & $0.43 * *$ & $0.86^{* *}$ \\
\hline Assimilation rate & $-0.813 * *$ & $-0.839 * *$ & $0.67 * *$ & $0.73^{* *}$ \\
\hline Production rate & $-0.854 * *$ & $-0.887 * *$ & $0.74 * *$ & $0.92 * *$ \\
\hline $\mathrm{AE}$ & $-0.673 * *$ & $-0.662 * *$ & $0.45 * *$ & $0.49 * *$ \\
\hline ECI & NS & NS & NS & NS \\
\hline ECD & $0.396^{*}$ & $0.604 *$ & $0.19 *$ & $0.39 *$ \\
\hline
\end{tabular}

* - Significance observed at $p=0.05$; ** - Significance observed at $p=0.01$ 

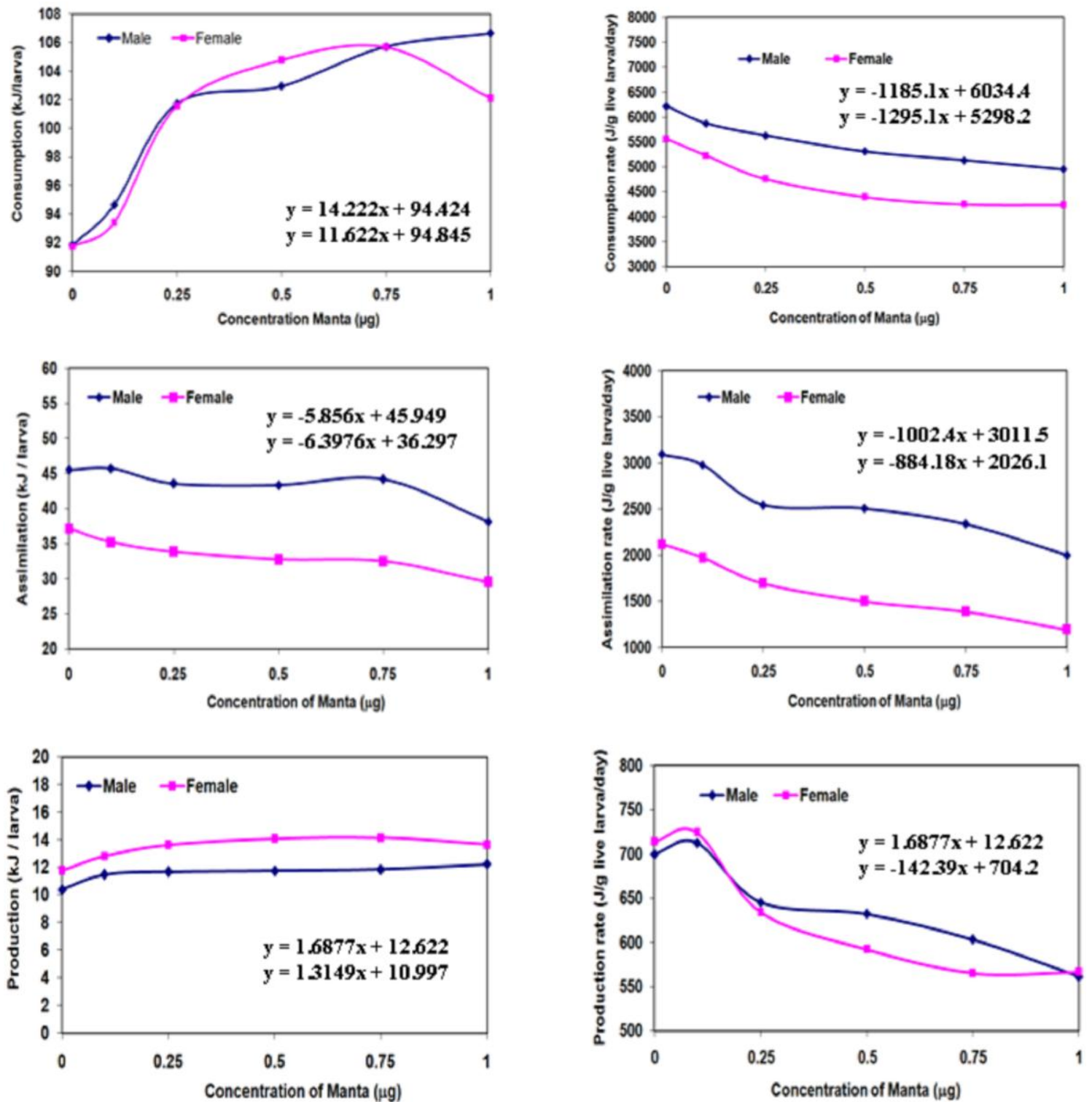

Fig. 1: Effect of Manta on consumption, assimilation and production rates of fifth instar larvae.

\section{Production rate}

As is evident the production rate of control male larvae was $699.83 \mathrm{~J} / \mathrm{g}$ live larva/day and it gradually decreased as the concentration of hormone increased excepting $0.1 \mu \mathrm{g}$ dose (Table 2, Figure 1). On relating dose of hormone applied to the production rate, a significant negative correlation was obtained $(\mathrm{r}=-0.854$ at $\mathrm{P}=0.01)$. A similar negative trend was observed in female larvae too. The control female larvae recorded a production rate of $714.12 \mathrm{~J} / \mathrm{g}$ live larva/day and the rate decreased to 566.67 $\mathrm{J} / \mathrm{g}$ live larva/day in the highest concentration of $1.0 \mu \mathrm{g}$, showing a negative correlation $(\mathrm{r}=-0.887$ at $\mathrm{P}=0.01)$.

\section{Assimilation efficiency (AE)}

The assimilation efficiency decreased with increasing concentration of hormone applied (Table 2, Figure 2). In control larvae, the $\mathrm{AE}$ was found to be maximum (49.16 and $40.14 \%$ in male and female respectively). In the highest dosage $(1.0 \mu \mathrm{g})$, the AE recorded for male $(35.45 \%)$ and female $(28.94 \%)$ was found to be minimum when compared to that of the other treatments.

A significant negative correlation was observed on relating the doses applied with $\mathrm{AE}(\mathrm{r}=-0.673$ for male and $\mathrm{r}=-$ 0.662 for female; $\mathrm{P}=0.01$ ). The data were found to be better fitted in a quadratic equation $\mathrm{Y}=48.58-14 \mathrm{x}+2 \mathrm{x}^{2}$ in male and $\mathrm{Y}=$ $39.16-22 x+12 x^{2}$ in female.

\section{Efficiency of conversion of ingested food (ECI)}

Though a marginal increase was recorded with respect to ECI in male and female larvae, in different treatments, it was found to be statistically not significant (Table 2, Figure 2). 

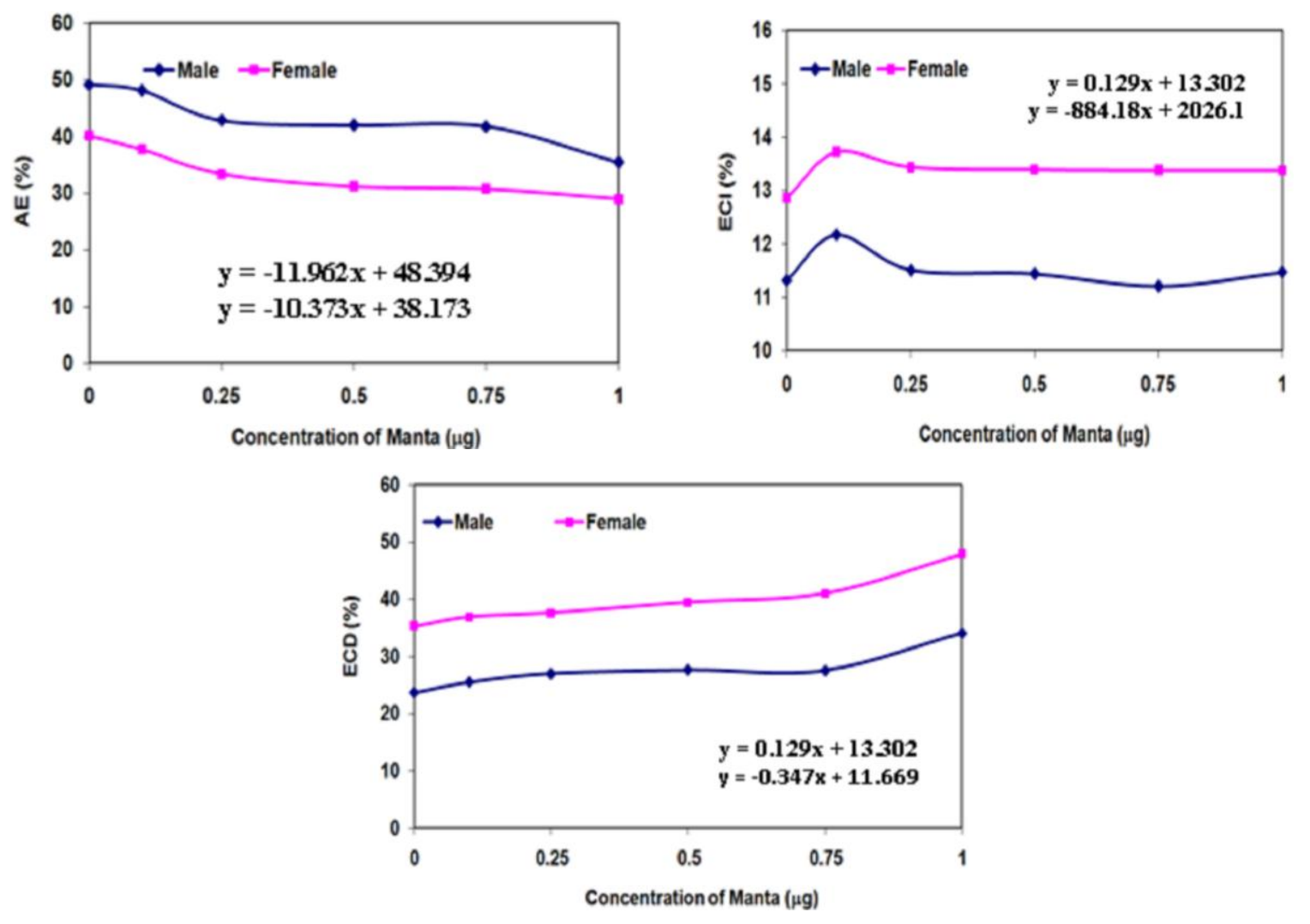

Fig. 2: Effect of Manta on the AE, ECI and ECD of fifth instar larvae.

\section{Efficiency of conversion of digested food (ECD)}

In male statistically significant results were obtained with respect to efficiency of conversion of digested food (Table 2, Figure 2). Of the five treatments, maximum ECD was recorded in $1.0 \mu \mathrm{g}$ dosage followed by $0.5 \mu \mathrm{g}$ and $0.75 \mu \mathrm{g}$ dosages which were on par with each other. The percentage elevation of $1.0 \mu \mathrm{g}$ dosage over control was 45. In female larvae, of the five treatments, maximum ECD was recorded in $1.0 \mu \mathrm{g}$ dosage (47.84 \%) which was followed by $0.75(41.01 \%)$ and $0.5 \mu \mathrm{g}$ dosages $(39.48 \%)$ when compared to that of the control (35.24\%). A significant positive correlation was observed in this study $(r=0.604)$ and data were fitted in quadratic equation $\left(Y=36.05+2 x+9 x^{2}\right)$.

\section{DISCUSSION}

A knowledge of what an insect consumes and the nutrients it assimilates enabled us to understand the nutritional physiology of the insect. Therefore a study on energetics of 5 th instar larvae of B. mori was pursued to understand the effect of application JHA, Manta on the pattern of flow of energy, conversion, utilization, assimilation and excretion i.e., the overall energy budget of this commercially important species. Proper understanding of the energy budget of the species can help in deciding the optimal dose in such a manner that the energy requirement for maintenance can be minimized and the production may be maximized for better commercial exploitation of the hormone (Mali and Khyade, 2010). Treatment with Manta in different dosages had a significant positive correlation with consumption, egestion and production and inverse correlation with assimilation of the silkworm B. mori. The secretion of ecdysteroids is affected by $\mathrm{JH}$ which modulates the timing of PTTH liberation and exerts an inhibitory action on ecdysteroid production from the prothoracic glands (Hartfelder, 2000). Treatment of last instar silkworms with persisting $\mathrm{JH}$ amounts to prevent the rise of ecdysteroids permanently. By affecting the release of PTTH which in the last instar silkworm is linked to the end of the obligatory feeding period, $\mathrm{JH}$ also influences the duration of indispensable feeding (Suzuki et al., 2013). Such modulatory effect of trace amounts of $\mathrm{JH}$ which are present in the last instar larvae, can be inferred from the observations that allatectomy at the start of the last instar reduces the length of the stadial period by two days and the body weight of larvae (Barman and Rajan, 2010).

In the present investigation, the application of Manta resulted in prolongation of larval period. As the larval period extended in the treated worms, the larvae consumed more food and this resulted in the increased body weight. This corroborates with the statement that remarked that a voraciously feeding larvae of $B$. mori should consume a higher quantity of food during an extended larval life (Paul et al., 1992). The digestive processes in insects are regulated by both secretogogue mechanisms and by hormonal influences (Woodring et al., 2007). The ingestion of Methoprene stimulated food consumption in the late instar caterpillars of Hyblaea puera (Muralideeran and Prabhu, 1981). Implantation of 
brain to raise the insect's own level of brain neurosecretion also stimulated food ingestion in Hyblaea. Caterpillars which either ingested Methoprene or received brain implants showed higher level of midgut amylase activity. It is also possible that $\mathrm{JH}$ affects only the food ingestion and that food ingested in turn directly stimulates midgut enzyme activity by a secretogogue mechanism. While recognising these uncertainities, the brain hormone regulates food consumption, possibly acting via a corpus allatum hormone (JH) in H. puera (Muralideeran and Prabhu, 1981).

Increased amounts of ingested food as a result of such regulation then seemed to stimulate midgut amylase activity, perhpas via a secretogogue mechanism. Since both the brain hormone and $\mathrm{JH}$ are known to affect general metabolism and since brain hormone affects the overall protein synthesis (Georgieff, 2007), the effects imparted by these hormones could explain the increased production. In the present study also application of Manta increased the consumption of larvae and consequently improved the larval weight. A correlation study relating different dosages of Manta with consumption, production and assimilation rates indicated a negative relationship. Despite increase in consumption and production perceived in the treated larvae, the rates were found to be decreased due to the extended larval duration. Assimilation efficiency was found to decrease with increase in the concentration of Manta applied. Cyclic AMP or adenyl cyclase phospho diesterase system plays an important role in the digestive function (Tengholm, 2002). The assimilation efficiency of larvae feeding on caffeine treated leaves suggested the probability that, caffeine by decreasing the cyclic AMP phosphodiesterase activity and thereby raising the cAMP level not only increases the rate of secretion of digestive glands but also increases the rate of absorption of digested food (Sano et al., 2013).

Therefore, in the present study, the decrease in the assimilation efficiency in relation to the increasing dose of Manta might be attributed to the decrease in the level of cAMP thus reducing the rate of secretion of digestive glands and also the rate of absorption of digested food, contributing to the increase in the quantity of egesta. This may account for the marginal increase in the ECI in the treated groups as compared to the control. However, a significant positive correlation observed between the increased dosage and efficiency of conversion of digested food (ECD) may suggest the possibility of efficient utilization of digested food into body substances.

\section{CONCLUSION}

From the overall energetics of the present study, it is clear that the concentration of Manta applied had a significant positive correlation with consumption, egestion, production and ECD. Of the dosages adminsitered, $0.75 \mu \mathrm{g}$ and $1.0 \mu \mathrm{g}$ dosages were found to be better treatments with regard to the parameters.

\section{REFERENCES}

Sehnal F, Akai H. Insect silk glands: their types, development and function and effects of environmental factors and morphogenetic hormones on them. Int J Insect Morphol Embyol, 1990; 19:79-132.

Unni BG, Bhattacharjee M, Goswami AM, Daschutia SB, Das S, Rajkhowa G, et al. Role of Insect Neuropeptides and Juvenile Hormones in Silk Protein Biosynthesis. Annal. Neurosci, 2010; 15(4):112-117.

Shibukawa A, Akai H. Effect of Manta on the silk production of a silkworm race producing heavy cocoon shells. J Seric Sci Jpn. 1981; 50:73-76.

Srivastava R, Upadhyay VB. Influence of bioactive phytojuvenoid on the silk producing potential of multivoltine mulberry silkworm (Bombyx mori Linn.). Int J Fauna Biol Stud, 2013;1(2):26-31.

Nagendraradhya BS, Jagadeesh Kumar TS. Effect of topical administration of $\mathrm{JH}$ mimic and performance of qualitative and quantitative traits of CSR2 and MG408 bivoltine breeds of the silkworm, Bombyx mori L. Int J Sci Environ Tech, 2013; 2(2):185-195.

Wu Z, Liu L, Chen G, Tan J. Induction, development and regulation of trimolters: Great progress in the domesticated silkworm (Bombyx mori L.). African J Biotechnol, 2013; 12(11):1171-1177.

Lokeshwari RK, Shantibala T. A review on the fascinating World of Insect resources: reason for thoughts. Psyche: J Entomol, 2010.

Miranda JE, Bortoli SAD and Takahashi R. Development and silk production by silkworm larvae after topical application of methoprene. Sci Agric, 2002; 59(3):585-588.

Mayanard AL, Loosili KJ. Animal Nutrition, 5th Edn. McGraw Hills, New York. 1962: p. 533.

Petrusewicz K, Macfadyen A. Productivity of Terrestrial animals. Blackwell Scientific Publications, Oxford, IBP Handbook, No.13 : 190, 1970.

Mali SG and Khyade VB. Influence of juvenile hormone analogue and insulin applied at third and fourth instar on some larval and cocoon characters in Bombyx mori L. J. Bio-Sci, 2010; 18:49-52.

Hartfelder K. Insect juvenile hormone: from "status quo" to high society. Braz J Med Biol Res, 2000; 33(2):157-177.

Suzuki Y, Koyama T, Hiruma K, Riddiford LM, Truman JW. A molt timer is involved in the metamorphic molt in Manduca sexta larvae. Proc Natl Acad Sci, 2013; 110(31):12518-12525.

Barman H, Rajan RK. Studies on Effects of Nutrient Supplements fortified with Phagostimulants Formulation H1 on growth and development of indoor reared Antheraea assamensis Helfer (Lepidoptera: Saturniidae). Int J Biol, 2010; 3(1): 167.

Paul DC, Subbarao G, Deb DC. Impact of dietary moisture on nutritional indices and growth of Bombyx mori and concommitant larval duration. J Insect Physiol, 1992; 38:229-235.

Woodring J, Hoffmann KH, Lorenz MW. Activity, release and flow of digestive enzymes in the cricket, Gryllus bimaculatus. Physiol Entomol, 2007; 32(1):56-63.

Muraleedharan D, Prabhu VKK. Hormonal influence on feeding and digestion on a plant bug, Dysdercus cingulatus and a catterpillar Hyblaea puera. Physiol Entomol, 1981; 6:183-189.

Georgieff MK. Nutrition and the developing brain: nutrient priorities and measurement. Am J Clin Nutn, 2007; 85(2):614S-620S.

Tengholm A. Cyclic AMP dynamics in the pancreatic $\beta$-cell. Upsala J Med Sci, 2012; 117(4):355-369.

Sano H, Kim YS, Choi YE. Like Cures Like: Caffeine Immunizes Plants Against Biotic Stresses. New Light on Alkaloid Biosynthesis and Future Prospects, 2013; 68:273-300.

How to cite this article:

Santhy K S. Rates of Feeding and Assimilation in the Silkworm, Bombyx mori, as Influenced by Methoprene. J App Pharm Sci, 2015; 5 (10): 101-106. 